\title{
Faecal microbiota transplantation: indications, evidence and safety
}

\section{Wei Ting Soo \\ Gastroenterology registrar? \\ Robert V Bryant \\ Consultant \\ gastroenterologist and \\ Head' \\ Senior clinical lecturer²}

\section{Samuel P Costello}

Consultant

gastroenterologist and

Head of research'

Senior clinical lecturer ${ }^{2}$

${ }^{1}$ Inflammatory Bowel

Disease Service,

Department of

Gastroenterology, Queen

Elizabeth Hospital, Adelaide

2 Faculty of Health Sciences,

School of Medicine,

University of Adelaide

\section{Keywords}

Clostridioides difficile, faecal microbiota transplantation, vancomycin

Aust Prescr 2020;43:36-8

https://doi.org/10.18773/ austprescr.2020.014

Corrected 2 June 2020

This is the corrected version of the article.

Correction notice

available at:

https://doi.org/10.18773/

austprescr.2020.032

\section{SUMMARY}

The human gut contains many species of microorganisms, many of which have a role in maintaining good health. The gut microbiota can be affected by diet, diseases and drugs, especially antibiotics.

Faecal microbiota transplantation involves transplanting faecal material from a healthy person to a patient, with the aim of treating disease. It is a recommended treatment option for patients with recurrent or refractory Clostridioides difficile as it has a cure rate over $90 \%$.

There is evidence that faecal microbiota transplantation can induce remission in ulcerative colitis, however maintenance of remission data are lacking. For other diseases it currently should not be used outside a clinical trial.

Stool donors have to be healthy and are screened for a range of diseases. As faecal material is usually transplanted during colonoscopy, the recipient must have bowel preparation before the procedure.

Adverse effects are mainly gastrointestinal and usually resolve in the week following transplantation. There are limited data on long-term safety.

\section{Introduction}

Faecal microbiota transplantation is the transfer of faecal material from a healthy individual to another person with the aim of treating a disease. It can be described as 'the ultimate probiotic' as it donates a much greater number and diversity of bacterial strains than any available probiotic.

The deliberate transfer of faecal material between individuals has a long history. It was first reported as a therapy in 4th century China. A human faecal suspension was given by mouth to treat patients with severe diarrhoea.' In North Africa camel faeces have been used as a treatment for dysentery. ${ }^{2}$ Human faecal microbiota transplantation was first described in the western literature in 1958 for the treatment of four critically ill patients with pseudomembranous colitis. ${ }^{3}$ The precise mechanisms by which faecal microbiota transplantation treats disease are not fully understood.

\section{Gut microbiome}

The organisms living in the gut are termed the gut microbiota, while the gut microbiome consists of the genetic material of these organisms. The human gastrointestinal microbiota contains approximately $3.9 \times 10^{13}$ organisms, a figure similar to the number of human cells in the body. ${ }^{4}$ It consists of bacteria, fungi, protozoa, archaea and viruses (including phage viruses that infect bacteria). The gut microbiota is dominated by two main phyla of bacteria - Firmicutes and Bacteroidetes. These make up 90\%, with eight other phyla making up the remaining $10 \% .^{5}$
Many of the microorganisms in the gut have co-evolved with humans and perform essential functions, such as the production of important metabolic products. For example, bacteria metabolise resistant starch in the colon to produce butyrate, a short chain fatty acid which is the primary and essential energy source of enteric colonocytes. ${ }^{6}$ Some intestinal microbiota live in close association with the colonic epithelium and play a role in regulating local and distant immune function. ${ }^{7}$ Others regulate intestinal barrier functions, or protect against pathogens such as vancomycinresistant enterococci by competitive inhibition. ${ }^{8}$

\section{Dysbiosis}

The gut microbiota is mostly acquired during the first 3-4 years of infancy, with mode of delivery, breastfeeding, diet and the local environment all playing a role. 9,10 Beyond this time the adult gut microbiome remains relatively stable. It can be altered by persistent dietary or lifestyle changes, disease, travel, drugs or surgery."

The use of systemic antibiotics is the most wellstudied risk factor for altering the gut microbiota. It results in a decreased diversity of species, loss of antimicrobial peptides produced by commensal bacteria, and loss of resistance to colonisation because the competitive inhibition of pathogens is reduced..$^{12}$ Perturbation of the gut microbiota associated with disease is termed dysbiosis. This has been associated with multiple diseases including Clostridioides difficile infection, colonisation with drug-resistant 
bacteria, inflammatory bowel disease, irritable bowel syndrome and metabolic syndrome..$^{13}$ These associations with dysbiosis have prompted research into possible aetiological roles that the microbiota may have and whether modification of the microbiota will have a therapeutic effect in these diseases.

\section{Indications}

At present, faecal microbiota transplantation is predominantly used for the treatment of $C$. difficile. Firstline treatment for mild $C$. difficile is oral metronidazole and, for more severe infection or recurrent episodes, vancomycin is recommended. ${ }^{14}$ Patients who have had two or more recurrences of $C$. difficile despite recommended antibiotic therapy have a low chance of responding to further antibiotic therapy. Transplantation offers a better chance of cure and its efficacy is supported by evidence from multiple randomised controlled trials. ${ }^{13,14} \mathrm{~A}$ single faecal transplant cures $80-90 \%$ of $C$. difficile cases, compared to cure rates of $26-30 \%$ with vancomycin, and repeated transplantation increases cure rates to more than 95\%. ${ }^{15}$ Evidence also supports the use of transplantation following severe $C$. difficile infection which has resulted in shock or supportive care, as well as in cases of disease refractory to antibiotic therapy. ${ }^{14,16-18}$ Faecal microbiota transplantation reduces cost and at the same time improves quality of life compared with vancomycin, saving over $A \$ 4,000$ per patient treated.$^{19}$ It is thus a recommended therapy for recurrent, refractory or severe C. difficile in national and international guidelines. ${ }^{14,16}$

There is evidence that faecal microbiota transplantation induces remission of active ulcerative colitis. 1718,20 However, more data are required before it can be recommended as maintenance therapy in ulcerative colitis. ${ }^{21}$

\section{Donor screening protocol}

Preferred stool donors are healthy people without pre-existing disease or risk factors for disease. These individuals are recruited by stool banks and undergo a thorough screening process that includes a questionnaire to exclude those with disease, exposure to transmissible diseases, or behavioural risk factors for transmissible diseases. Disease exclusions include, but are not limited to, blood- or stool-borne infections, gastrointestinal disorders, malignancy, atopy, metabolic syndrome and autoimmune diseases. People who have recently taken antibiotics or have travelled to areas with a high risk of traveller's diarrhoea are excluded. BMI is then calculated and those who are obese or underweight are excluded.

Donors who pass the screening questionnaire and $\mathrm{BMI}$ measure then undergo extensive blood and stool tests for transmissible diseases. This includes checking for blood- and stool-borne infections and multidrug resistant organisms in the stool.

\section{Preparation and delivery}

Currently there is no universal protocol for preparing a patient for faecal microbiota transplantation. Stool is usually mixed with saline or water with between $12.5 \%$ and $25 \%$ stool in the suspension by weight. The transplant can be fresh or thawed frozen stool as these are equally effective. ${ }^{22}$ When freezing stools $10 \%$ glycerol is often added to preserve bacterial viability. ${ }^{23}$

Patients preparing to receive a faecal microbiota transplantation for $C$. difficile are required to take vancomycin for 5-10 days and then stop 24-36 hours before the procedure. For colonoscopic delivery, patients undergo bowel preparation approximately 12 hours before the procedure. On the day it is common for the patient to be given loperamide to assist with retaining the transplanted material. ${ }^{24}$

The methods of delivery are via the upper gastrointestinal route (nasoduodenal, oral capsules), or lower gastrointestinal route (colonoscopic delivery into the ascending colon, or retention enemas). However, colonoscopic delivery is the most common method. It has the most evidence in the literature, with high rates of cure across studies. ${ }^{25}$ Nasogastric and nasoduodenal delivery tend to have higher rates of minor adverse effects relative to other methods. ${ }^{15}$

\section{Safety}

Faecal microbiota transplantation for recurrent $C$. difficile has a good short-term safety record. There are very few adverse effects directly attributed to the procedure. Most reported adverse events have been self-limiting gastrointestinal symptoms including abdominal cramps, diarrhoea and constipation, which resolved within one week. ${ }^{25}$ There have been at least two deaths from aspiration pneumonia related to sedation given at the time of faecal microbiota transplantation. There has been at least one death from transmission of a multidrug resistant Escherichia coli organism, however the donor in this case had not been tested for this organism. ${ }^{26}$ These deaths are relatively small in number compared to the large number of transplantations performed (at least 50,000 in the USA since 2013). ${ }^{27}$

The long-term safety of faecal microbiota transplantation is not yet well established. Most of the studies have only been reported in the last decade and there have been no registries until recently.

\section{Emerging indications}

A large number of diseases have been associated with gut dysbiosis and the success of faecal microbiota transplantation in treating recurrent $C$. difficile has encouraged research into transplantation as a potential therapy for these diseases. There have been trials in irritable bowel syndrome, ${ }^{28-30}$ hepatic encephalopathy, ${ }^{31}$ Crohn's disease, ${ }^{32}$ primary sclerosing cholangitis ${ }^{33}$ and autism. ${ }^{34}$ However, the evidence for the efficacy and safety of faecal microbiota transplantation for these 
conditions is currently limited and further studies are warranted before it can be recommended as therapy outside of clinical trials. While trials have the possibility of broadening the indications for transplantation, they could also guide the development of microbial therapeutics that may replace or complement faecal microbiota transplantation in the future.

\section{Conclusion}

Faecal microbiota transplantation is an effective

treatment option for recurrent infection with

\section{C. difficile. Its use in other indications at present} should be part of a clinical trial. $<$

Robert V Bryant has received speaker fees, grants and research support from AbbVie, Ferring, Janssen, Shire, Takeda and Emerge Health. These fees were paid to his employer to support research. He is also a board member and shareholder of BiomeBank.

Samuel P Costello has received speaker fees, grants and research support from Ferring, Janssen, Shire and Microbiotica. He is also a board member and shareholder of BiomeBank.

\section{REFERENCES}

1. Zhang F, Luo W, Shi Y, Fan Z, Ji G. Should we standardize the 1,700-year-old fecal microbiota transplantation? Am J Gastroenterol 2012;107:1755. https://doi.org/10.1038/ajg.2012.251

2. Lewin RA. More on Merde. Perspect Biol Med 2001:44:594-607. https://doi.org/10.1353/pbm.2001.0067

3. Eiseman B, Silen W, Bascom GS, Kauvar AJ. Fecal enema as an adjunct in the treatment of pseudomembranous enterocolitis. Surgery 1958;44:854-9.

4. Sender R, Fuchs S, Milo R. Are we really vastly outnumbered? Revisiting the ratio of bacterial to host cells in humans. Cell 2016;164:337-40. https://doi.org/ 10.1016/j.cell.2016.01.013

5. Almeida A, Mitchell AL, Boland M, Forster SC, Gloor GB, Tarkowska A, et al. A new genomic blueprint of the human gut microbiota. Nature 2019;568:499-504. https://doi.org/10.1038/s41586-019-0965-1

6. Roediger WE, Millard S. Colonocyte metabolism. Gut 1996;38:792-3. https://doi.org/10.1136/gut.38.5.792-a

7. Kaparakis-Liaskos M, Ferrero RL. Immune modulation by bacterial outer membrane vesicles. Nat Rev Immunol 2015;15:375-87. https://doi.org/10.1038/nri3837

8. Roy S, Trinchieri G. Microbiota: a key orchestrator of cancer therapy. Nat Rev Cancer 2017;17:271-85. https://doi.org/10.1038/nrc.2017.13

9. Dominguez-Bello MG, Costello EK, Contreras M, Magris M, Hidalgo G, Fierer N et al. Delivery mode shapes the acquisition and structure of the initial microbiota across multiple body habitats in newborns. Proc Natl Acad Sci USA 2010;107:11971-5. https://doi.org/10.1073/pnas.1002601107

10. Collado MC, Rautava S, Aakko J, Isolauri E, Salminen S. Human gut colonisation may be initiated in utero by distinct microbial communities in the placenta and amniotic fluid. Sci Rep 2016;6:23129. https://doi.org/10.1038/srep23129

11. Lax S, Smith DP, Hampton-Marcell J, Owens SM, Handley KM, Scott NM, et al. Longitudinal analysis of microbial interaction between humans and the indoor environment. Science 2014;345:1048-52. https://doi.org/10.1126/ science.1254529

12. Buffie CG, Pamer EG. Microbiota-mediated colonization resistance against intestinal pathogens. Nat Rev Immunol 2013;13:790-801. https://doi.org/ 10.1038/nri3535

13. Smits LP, Bouter KE, de Vos WM, Borody TJ, Nieuwdorp M. Therapeutic potential of fecal microbiota transplantation. Gastroenterology 2013;145:946-53. https://doi.org/10.1053/j.gastro.2013.08.058

14. Trubiano JA, Cheng AC, Korman TM, Roder C, Campbell A, May ML, et al. Australasian Society of Infectious Diseases updated guidelines for the management of Clostridium difficile infection in adults and children in Australia and New Zealand. Intern Med J 2016;46:479-93. https://doi.org/ 10.1111/imj.13027

15. Ianiro G, Maida M, Burisch J, Simonelli C, Hold G, Ventimiglia M, et al. Efficacy of different faecal microbiota transplantation protocols for Clostridium difficile infection: a systematic review and meta-analysis. United European Gastroenterol J 2018;6:1232-44. https://doi.org/10.1177/2050640618780762

16. MCDonald LC, Gerding DN, Johnson S, Bakken JS, Carroll KC, Coffin SE, et al. Clinical practice guidelines for Clostridium difficile infection in adults and children: 2017 update by the Infectious Diseases Society of America (IDSA) and Society for Healthcare Epidemiology of America (SHEA). Clin Infect Dis 2018;66:e1-48. https://doi.org/10.1093/cid/cix1085

17. Costello SP, Hughes PA, Waters O, Bryant RV, Vincent AD, Blatchford P, et al. Effect of fecal microbiota transplantation on 8-week remission in patients with ulcerative colitis: a randomized clinical trial. JAMA 2019;321:156-64. https://doi.org/10.1001/jama.2018.20046

18. Costello SP, Soo W, Bryant RV, Jairath V, Hart AL, Andrews JM. Systematic review with meta-analysis: faecal microbiota transplantation for the induction of remission for active ulcerative colitis. Aliment Pharmacol Ther 2017;46:213-24 https://doi.org/10.1111/apt.14173
19. Merlo G, Graves N, Brain D, Connelly LB. Economic evaluation of fecal microbiota transplantation for the treatment of recurrent Clostridium difficile infection in Australia. J Gastroenterol Hepatol 2016;31:1927-32. https://doi.org/10.1111/jgh.13402

20. Paramsothy S, Kamm MA, Kaakoush NO, Walsh AJ, van den Bogaerde J, Samuel D, et al. Multidonor intensive faecal microbiota transplantation for active ulcerative colitis: a randomised placebo-controlled trial. Lancet 2017;389:1218-28. https://doi.org/10.1016/S0140-6736(17)30182-4

21. Haifer C, Kelly CR, Paramsothy S, Andresen D, Papanicolas LE, McKew GL, et al. Australian consensus statements for the regulation, production and use of faecal microbiota transplantation in clinical practice. Gut 2020 Feb 11 [Epub ahead of print]. https://doi.org/10.1136/gutjnl-2019-320260

22. Lee $\mathrm{CH}$, Steiner T, Petrof EO, Smieja M, Roscoe D, Nematallah A, et al. Frozen vs fresh fecal microbiota transplantation and clinical resolution of diarrhea in patients with recurrent clostridium difficile infection: a randomized clinical trial. JAMA 2016;315:142-9. https://doi.org/10.1001/jama.2015.18098

23. Costello SP, Conlon MA, Vuaran MS, Roberts-Thomson IC, Andrews JM. Faecal microbiota transplant for recurrent Clostridium difficile infection using longterm frozen stool is effective: clinical efficacy and bacterial viability data. Aliment Pharmacol Ther 2015:42:1011-8. https://doi.org/10.1111/apt 13366

24. Costello SP, Tucker EC, La Brooy J, Schoeman MN, Andrews JM. Establishing a fecal microbiota transplant service for the treatment of Clostridium difficile infection. Clin Infect Dis 2016:62:908-14. https://doi.org/10.1093/cid/civ994

25. Quraishi MN, Widlak M, Bhala N, Moore D, Price M, Sharma N, et al. Systematic review with meta-analysis: the efficacy of faecal microbiota transplantation for the treatment of recurrent and refractory Clostridium difficile infection. Aliment Pharmacol Ther 2017;46:479-93. https://doi.org/10.1111/apt.14201

26. DeFilipp Z, Bloom P, Soto M, Mansour M, Sater M, Huntley M, et al. Drugresistant $E$. coli bacteraemia transmitted by fecal microbiota transplant N Engl J Med 2019; 381: 2043-2050. https://doi.org/10.1056/NEJMoa1910437

27. Openbiome. [Internet]. www.openbiome.org/impact [cited 2020 Mar 1]

28. Ianiro G, Eusebi LH, Black CJ, Gasbarrini A, Cammarota G, Ford AC. Systematic review with meta-analysis: efficacy of faecal microbiota transplantation for the treatment of irritable bowel syndrome. Aliment Pharmacol Ther 2019;50:240-8. https://doi.org/10.1111/apt.15330

29. Halkjær SI, Christensen AH, Lo BZ, Browne PD, Günther S, Hansen LH, et al. Faecal microbiota transplantation alters gut microbiota in patients with irritable bowel syndrome: results from a randomised, double-blind placebo-controlled study. Gut 2018;67:2107-15. https://doi.org/10.1136/gutjnl-2018-316434

30. Johnsen $\mathrm{PH}$, Hilpüsch F Cavanagh JP, Leikanger IS, Kolstad C, Valle PC, et al. Faecal microbiota transplantation versus placebo for moderate-to-severe irritable bowel syndrome: a double-blind, randomised, placebo-controlled, parallel-group, single-centre trial. Lancet Gastroenterol Hepatol 2018;3:17-24 https://doi.org/10.1016/S2468-1253(17)30338-2

31. Bajaj JS, Kassam Z, Fagan A, Gavis EA, Liu E, Cox IJ, et al. Fecal microbiota transplant from a rational stool donor improves hepatic encephalopathy: a randomized clinical trial. Hepatology 2017;66:1727-38. https://doi.org/10.1002/ hep.29306

32. Paramsothy S, Paramsothy R, Rubin DT, Kamm MA, Kaakoush NO, Mitchell HM, et al. Faecal microbiota transplantation for inflammatory bowel disease: a systematic review and meta-analysis. J Crohn's Colitis 2017;11:1180-99. https://doi.org/10.1093/ecco-jcc/jix063

33. Allegretti JR, Kassam Z, Carrellas M, Mullish BH, Marchesi JR, Pechlivanis A, et al. Fecal microbiota transplantation in patients with primary sclerosing cholangitis: a pilot clinical trial. Am J Gastroenterol 2019;114:1071-9. https://doi.org/10.14309/ajg.0000000000000115

34. Kang DW, Adams JB, Gregory AC, Borody T, Chittick L, Fasano A, et al. Microbiota transfer therapy alters gut ecosystem and improves gastrointestinal and autism symptoms: an open-label study. Microbiome 2017;5:10. https://doi.org/10.1186/s40168-016-0225-7 